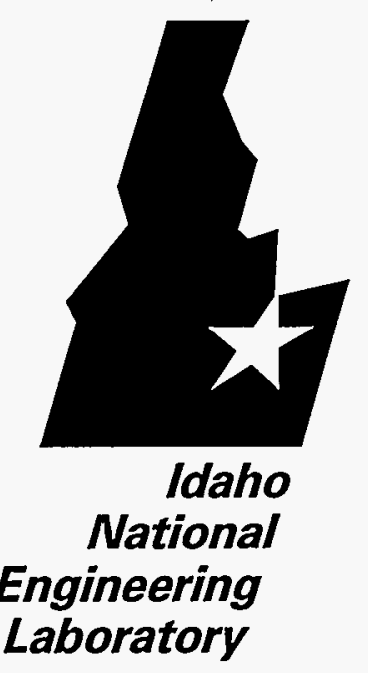

INEL-95/0260

May 1995

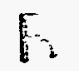

Fo2 $2310 \%$

OSTI

Laser-Assisted Electrochemistry

D. F. Glenn

戸나ockheed

Idaho Technologies Company 


+




\section{Laser-Assisted Electrochemistry}

D. F. Glenn

Published May 1995

Idaho National Engineering Laboratory Applied Materials and Technology

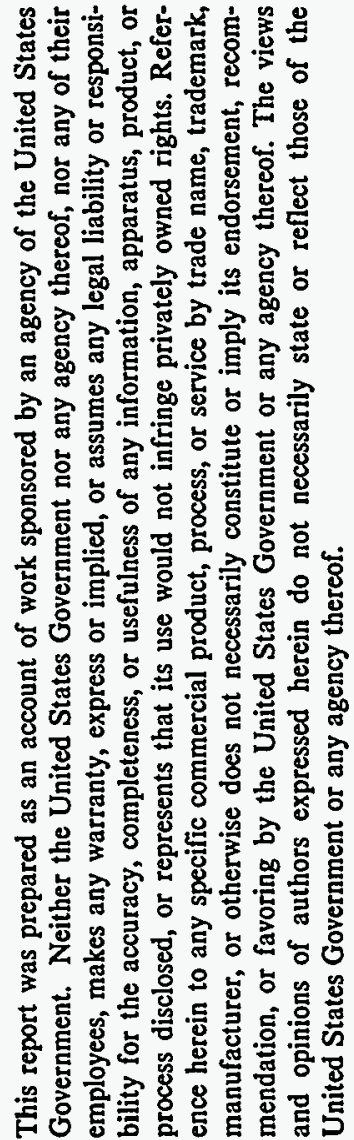

Lockheed Idaho Technologies Company Idaho Falls, Idaho 83415 


\begin{abstract}
The effect of laser irradiation on the electrodeposition of various metals and alloys has been investigated. It was found that laser irradiation of the cathode during the electrodeposition of metals results in higher plating rates, increased current efficiency, and improved morphology of the resultant electrodeposit. In the case of chromium electrodeposition, plating rates as high as $120 \mathrm{mils} / \mathrm{h}$ were observed with the addition of laser irradiation to the process. Experimental evidence has been obtained that indicates that the mechanism responsible for the very high plating rates is the result of a laser-induced Soret effect.
\end{abstract}





\section{CONTENTS}

ABSTRACT $\ldots \ldots \ldots \ldots \ldots \ldots \ldots \ldots \ldots \ldots \ldots \ldots \ldots \ldots \ldots \ldots \ldots \ldots \ldots$

INTRODUCTION $\ldots \ldots \ldots \ldots \ldots \ldots \ldots \ldots \ldots \ldots \ldots \ldots \ldots \ldots \ldots \ldots \ldots \ldots \ldots$

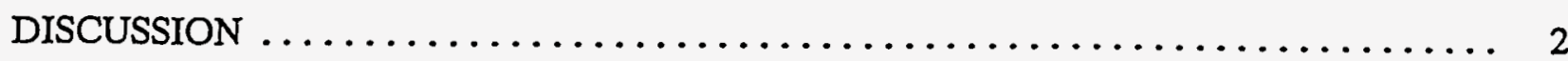

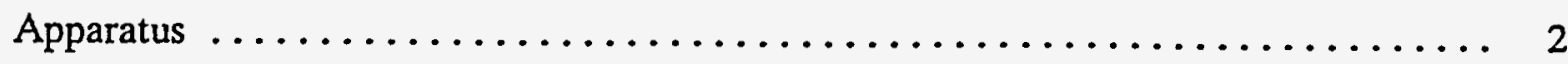

Single Metal Deposition $\ldots \ldots \ldots \ldots \ldots \ldots \ldots \ldots \ldots \ldots \ldots \ldots \ldots \ldots \ldots \ldots$

Electrode Temperature $\ldots \ldots \ldots \ldots \ldots \ldots \ldots \ldots \ldots \ldots \ldots \ldots \ldots \ldots \ldots$

Electroplating Enhancement Mechanism $\ldots \ldots \ldots \ldots \ldots \ldots \ldots \ldots \ldots \ldots \ldots$

Alloy Plating $\ldots \ldots \ldots \ldots \ldots \ldots \ldots \ldots \ldots \ldots \ldots \ldots \ldots \ldots \ldots \ldots$

Difficult-to-Deposit Metals $\ldots \ldots \ldots \ldots \ldots \ldots \ldots \ldots \ldots \ldots \ldots \ldots \ldots \ldots \ldots$

Electrochemical Milling $\ldots \ldots \ldots \ldots \ldots \ldots \ldots \ldots \ldots \ldots \ldots \ldots \ldots \ldots \ldots \ldots$

Hydrogen Evolution Reaction $\ldots \ldots \ldots \ldots \ldots \ldots \ldots \ldots \ldots \ldots \ldots \ldots \ldots \ldots \ldots$

Oxygen Evolution Reaction $\ldots \ldots \ldots \ldots \ldots \ldots \ldots \ldots \ldots \ldots \ldots \ldots \ldots \ldots \ldots$

CONCLUSIONS $\ldots \ldots \ldots \ldots \ldots \ldots \ldots \ldots \ldots \ldots \ldots \ldots \ldots \ldots \ldots \ldots \ldots \ldots$

REFERENCES $\ldots \ldots \ldots \ldots \ldots \ldots \ldots \ldots \ldots \ldots \ldots \ldots \ldots \ldots \ldots \ldots \ldots \ldots \ldots$

\section{FIGURES}

1. Schematic of the experimental apparatus $\ldots \ldots \ldots \ldots \ldots \ldots \ldots \ldots \ldots \ldots \ldots$

2. Diagram of free jet $\ldots \ldots \ldots \ldots \ldots \ldots \ldots \ldots \ldots \ldots \ldots \ldots \ldots \ldots \ldots \ldots \ldots$

3. Effect of laser irradiation on the electrodeposition of chromium $\ldots \ldots \ldots \ldots$

4. SEM photographs of chromium electroplate $\ldots \ldots \ldots \ldots \ldots \ldots \ldots \ldots \ldots \ldots$

5. Linear sweep voltammograms of chromium solution with and without laser irradiation from an $\mathrm{ND}: \mathrm{YAG}$ laser $\ldots \ldots \ldots \ldots \ldots \ldots \ldots \ldots \ldots \ldots \ldots \ldots \ldots$

6. Open-circuit potential shift with the laser irradiation of the cathode $\ldots \ldots \ldots \ldots$

7. Soret effect from a model by Smalley et al .................... 9 
8. Tafel plots for the HER on Pt in $0.5 \mathrm{M} \mathrm{H}_{2} \mathrm{SO}_{4}$ without laser irradiation $(\mathrm{P}=0)$ and with laser irradiation $(\mathrm{P}=130$, 800 , and $2,300 \mathrm{~W} / \mathrm{cm}^{2}$ )

9. Tafel plots for the OER on Pt in $1 \mathrm{M} \mathrm{H}_{2} \mathrm{SO}_{4}$ without laser irradiation $(P=0)$ and with laser irradiation $\left(P=2,300 \mathrm{~W} / \mathrm{cm}^{2}\right) \ldots \ldots \ldots \ldots \ldots$

\section{TABLES}

1. Plating conditions $\ldots \ldots \ldots \ldots \ldots \ldots \ldots \ldots \ldots \ldots \ldots \ldots \ldots \ldots \ldots \ldots \ldots \ldots \ldots, 4$

2. Composition of iron-nickel electroplate as a function of applied current, with and without laser irradiation

3. Tafel parameters for HER as a function of laser power density $\ldots \ldots \ldots \ldots \ldots \ldots$ 


\section{Laser-Assisted Electrochemistry}

\section{INTRODUCTION}

The purpose of this research was to develop a fundamental understanding of how intense photon beams affect electrochemical processes and to determine the mechanisms by which these effects occur. During FY-90 and FY-91, scoping studies were conducted to determine the effect of laser irradiation of the cathode during the electrodeposition of single metals and alloys. The intent of these scoping studies was to determine when and where the laser had an effect before detailed mechanistic studies were undertaken. In FY-90, the laser's effect on single metal electrodeposition processes, such as copper, nickel, and chromium, was investigated. Work in FY-91 explored effects of laser irradiation during the complex deposition of alloys and on single metals that cannot normally be electrodeposited from aqueous solutions. These scoping studies demonstrated that the addition of laser irradiation to electroplating processes can dramatically enhance plating rates, current efficiencies, and hardness, as well as alter the morphology of the resultant electrodeposit. These scoping studies also pointed out situations where high-energy photons have little or no effect on the deposition process.

In FY-92, studies were conducted to determine the mechanism(s) responsible for the previously observed laser enhancement of electrodeposition processes. Experimental efforts centered around a study of the effect of laser irradiation on the hydrogen evolution reaction (HER). This reaction is a competing reaction in many electrodeposition processes, and it was felt that a study of the laser's effect on this reaction would provide insight into the enhancement mechanism. Additional studies were undertaken to determine the effect of laser irradiation on the oxygen evolution reaction (OER) because of the importance of this reaction in various electrochemical processes. During the course of these investigations, the mechanism for the laser enhancement of electrochemical processes was determined. Experimental evidence was obtained to show that laser irradiation of the substrate results in increased metal ion concentrations at the surface of the electrode due to a laser-induced Soret effect. This increased surface concentration results in increased plating rates and current efficiencies and in electrodeposition at potentials less negative than those required by the bulk concentration of metal ions. 


\section{DISCUSSION}

\section{Apparatus}

A schematic of the laboratory-scale Laser-Jet Electroplating System constructed for this investigation is shown in Figure 1. The basic elements of the system are the laser, spray gun containing the anode, cathode, and potentiostat. Not shown in this schematic are the solution reservoir and pump to recirculate plating solutions after impingement on the cathode. The laser beam was directed to the impingement region of the jet from the side of the nozzle, striking the electrode at a 60-degree angle. This configuration allowed all of the laser energy to reach the surface of the cathode. No energy was lost due to absorption of the beam by the liquid in the jet. Laser assistance was provided by a $100 \mathrm{~W}$ ND:YAG $(1,060 \mathrm{~nm})$ laser or a $20 \mathrm{~W}$ Argon Ion Laser $(540 \mathrm{~nm})$ depending upon the experiments being run. The laser beam diameter was adjusted with an objective lens, positioned at a specific distance from the cathode such that the beam diameter would be roughly equal to the diameter of the jet impingement region $(-3 \mathrm{~mm})$ on the surface of the cathode.

The principal advantage of using an impinging jet is its ability to provide a rapid resupply of ions to the plating region. This overcomes the usual mass transport limited plating rates that arise at high-current densities. Additionally, the jet allows any heating from laser irradiation to be highly localized; little energy is wasted in heating the bulk solution. The cooling capacity of the jet also prevents heat buildup in the working electrode. A small diameter nozzle $(0.5 \mathrm{~mm})$ was used to obtain high flow rates while limiting the amount of plating solution required for each experiment. The nozzle-to-cathode spacing in this system is typically $3 \mathrm{~mm}$. All plating experiments were carried out with the plating solutions at room temperature.

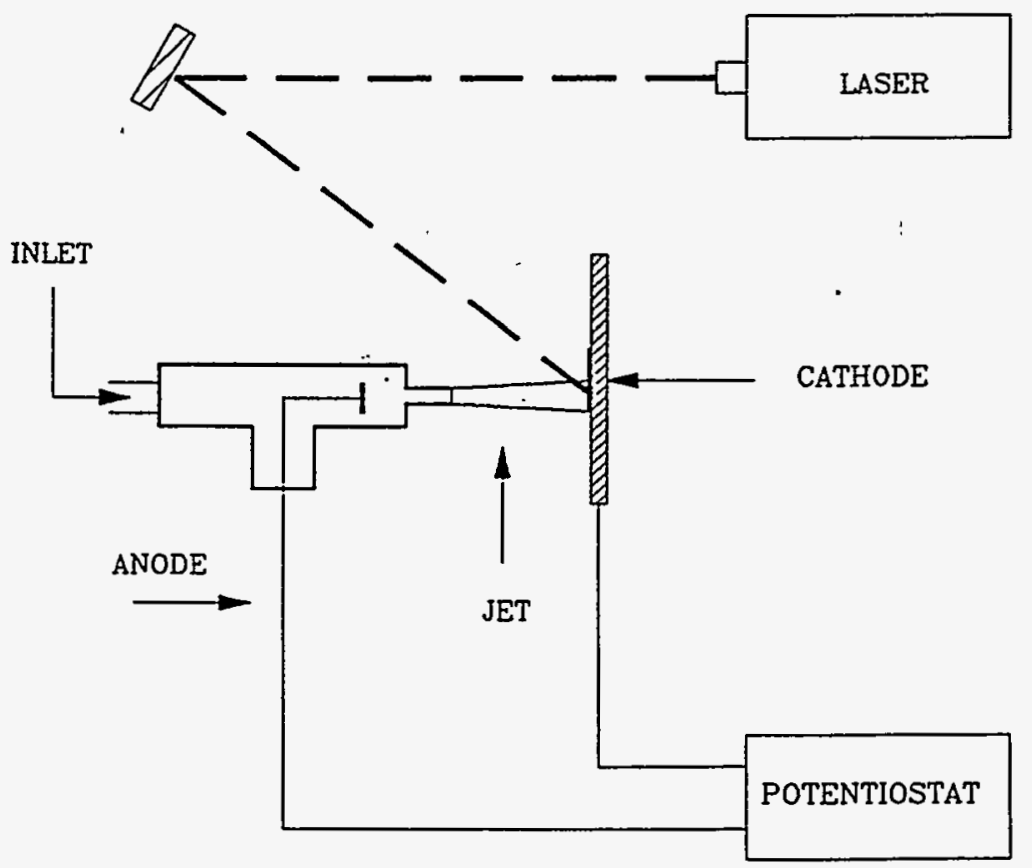

Figure 1. Schematic of experimental apparatus. 
The apparatus shown in Figure 1 produces a free-standing jet of electrolyte that impinges normal to the planar cathode. The complex fluid flow patterns of the free-standing jet are shown in Figure 2. Flow is generally divided into three fundamental regions: the free-jet region near the nozzle, the stagnation region near the impingement area, and the "wall-jet" region. The wall-jet region contains a relatively thin layer of fluid formed by the deflection of the free jet. Electroplating from the jet system results in metal being selectively deposited in the stagnation region, with little or no deposition in the wall jet.

The selectivity of deposition with the jet electroplating system is attributed to the fact that the anode is located behind the nozzle in the upstream portion of the jet. Consequently, the only current path in this electrochemical cell is the free jet itself. The current density would then be expected to be highest in the stagnation region and to decline rapidly as the jet expands in the radial direction. Plating in the wall-jet can be expected to be proportionally smaller because the current density in the radial direction is much smaller, due to the high resistance of the thin layer of fluid. With the cathode held stationary, electroplating with this system produces a circular spot of metal approximately $3 \mathrm{~mm}$ in diameter depending on flow rate, applied current, solution concentration, and laser power.

\section{Single Metal Deposition}

With this system, nickel, copper, iron, zinc, and chromium were electrodeposited. Electrodeposition was carried out at constant current on copper foil cathodes. Laser irradiation of the cathode during the electroplating process was found to increase the rate of metal deposition, increase the current efficiency, and alter the morphology of the electroplate. This was true for each of the metals studied. However, the most dramatic laser effects were seen in the deposition of chromium.

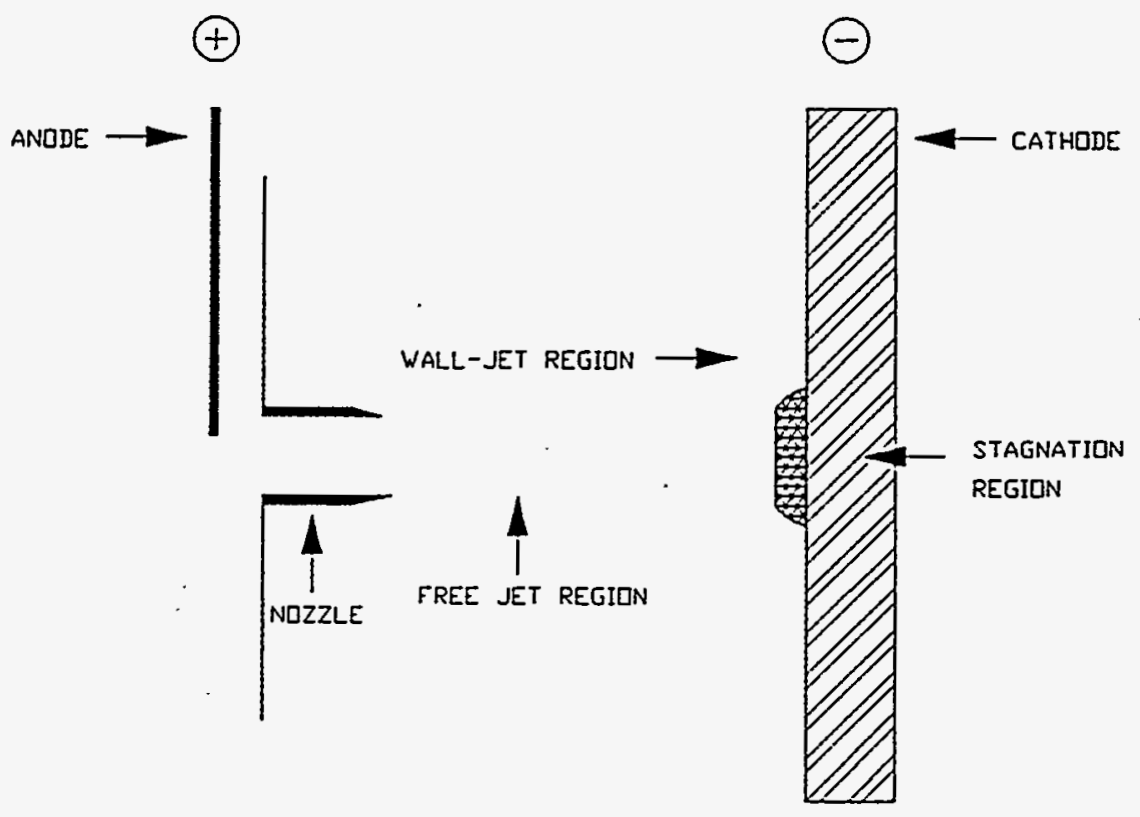

Figure 2. Diagram of free jet. 
Figure 3 illustrates the effect of laser irradiation on the deposition rate of chromium as a function of applied current under the conditions shown in Table 1. Without laser irradiation, the plating rate is seen to increase with increasing applied current. At an applied current of $150 \mathrm{~mA}$, the plating rate reaches a maximum of $50 \mathrm{mils} / \mathrm{h}$. At this applied current, the current efficiency is $30 \%$. Increasing the applied current above $150 \mathrm{~mA}$ had no effect on the rate of metal deposition. Increasing the flow rate had no significant effect on plating rate at this solution concentration.

With laser assistance from a ND:YAG laser, the plating rate increases with increasing applied current up to the highest current possible from the potentiostat. The plating rate reaches $120 \mathrm{mils} / \mathrm{h}$ at $230 \mathrm{~mA}$. This is a $240 \%$ laser enhancement over jet plating. The current efficiency

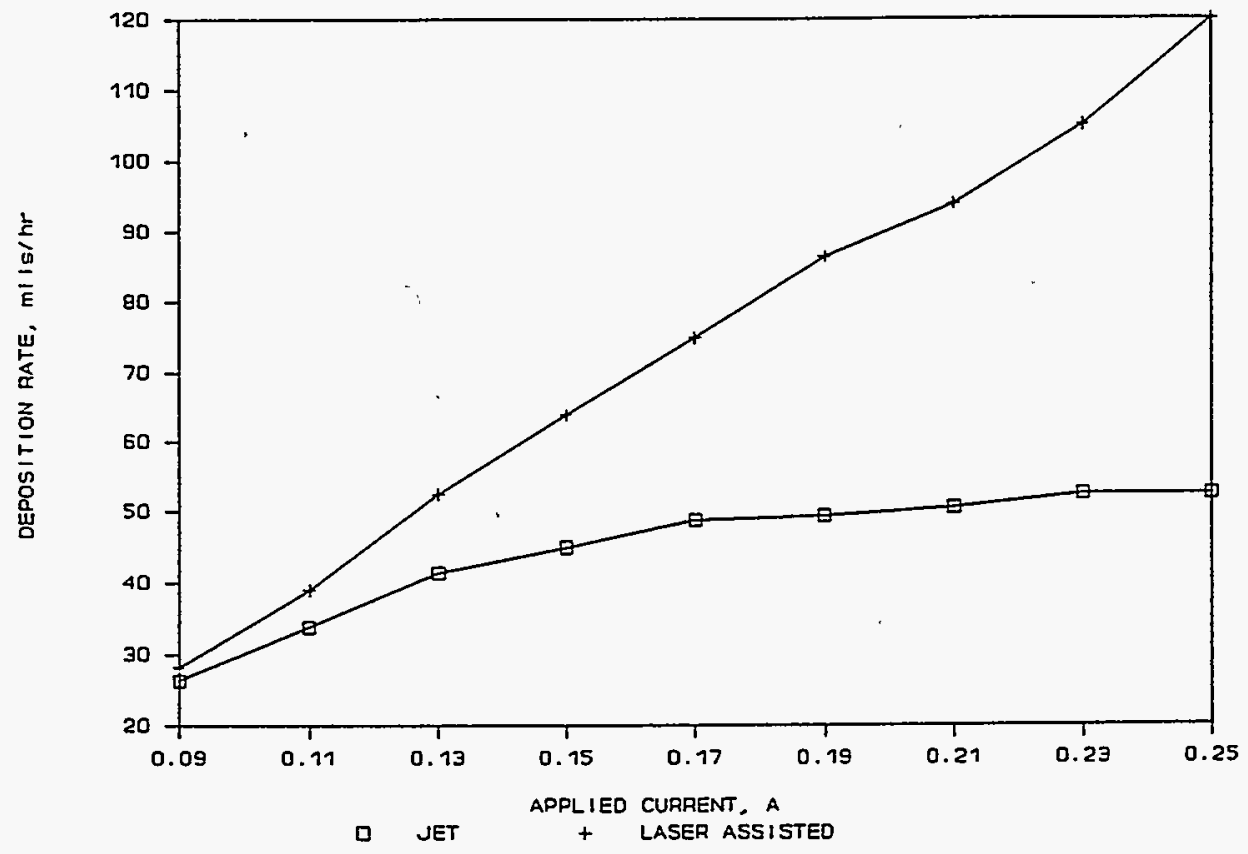

Figure 3. Effect of laser irradiation on the electrodeposition of chromium.

Table 1. Plating conditions.

Solution

Solution temperature

Nozzle diameter

Nozzle-cathode spacing

Flow rate

Current density

Laser

$\mathrm{Cw}$ power
$2.0 \mathrm{MCrO}_{3}, 0.02 \mathrm{M} \mathrm{H}_{2} \mathrm{SO}_{4}$

$20^{\circ} \mathrm{C}$

$0.5 \mathrm{~mm}$

$3 \mathrm{~mm}$

$280 \mathrm{~mL} / \mathrm{min}$

$0.5-4 \mathrm{~A} / \mathrm{cm}_{2}$

ND:YAG

$2,300 \mathrm{~W} / \mathrm{cm}_{2}$ 
under these conditions was calculated to be $60 \%$. No significant difference in deposition rate or current efficiency was seen between laser irradiation at 1,060 nm (ND:YAG) and $514 \mathrm{~nm}$ (Argon Ion).

The laser-assisted plating rate for chromium of $120 \mathrm{mils} / \mathrm{h}$ is two orders of magnitude higher than the plating ratc of a typical bath plating system $(1 \mathrm{mil} / \mathrm{h})$ for chromium. The current efficiency of $60 \%$ is 4 times that of bath plating (15\%). This plating rate and efficiency are the highest yet reported for chromium. It should be noted that these increases were achieved using a solution that contained only half the concentration of metal ions present in a standard bath plating solution.

Laser irradiation of the electrode during electrodeposition also had a marked effect on the morphology of the electrodeposit. Scanning electron micrographs of the surface of the chromium deposited both with and without the laser are shown in Figure 4. Without laser assistance, the
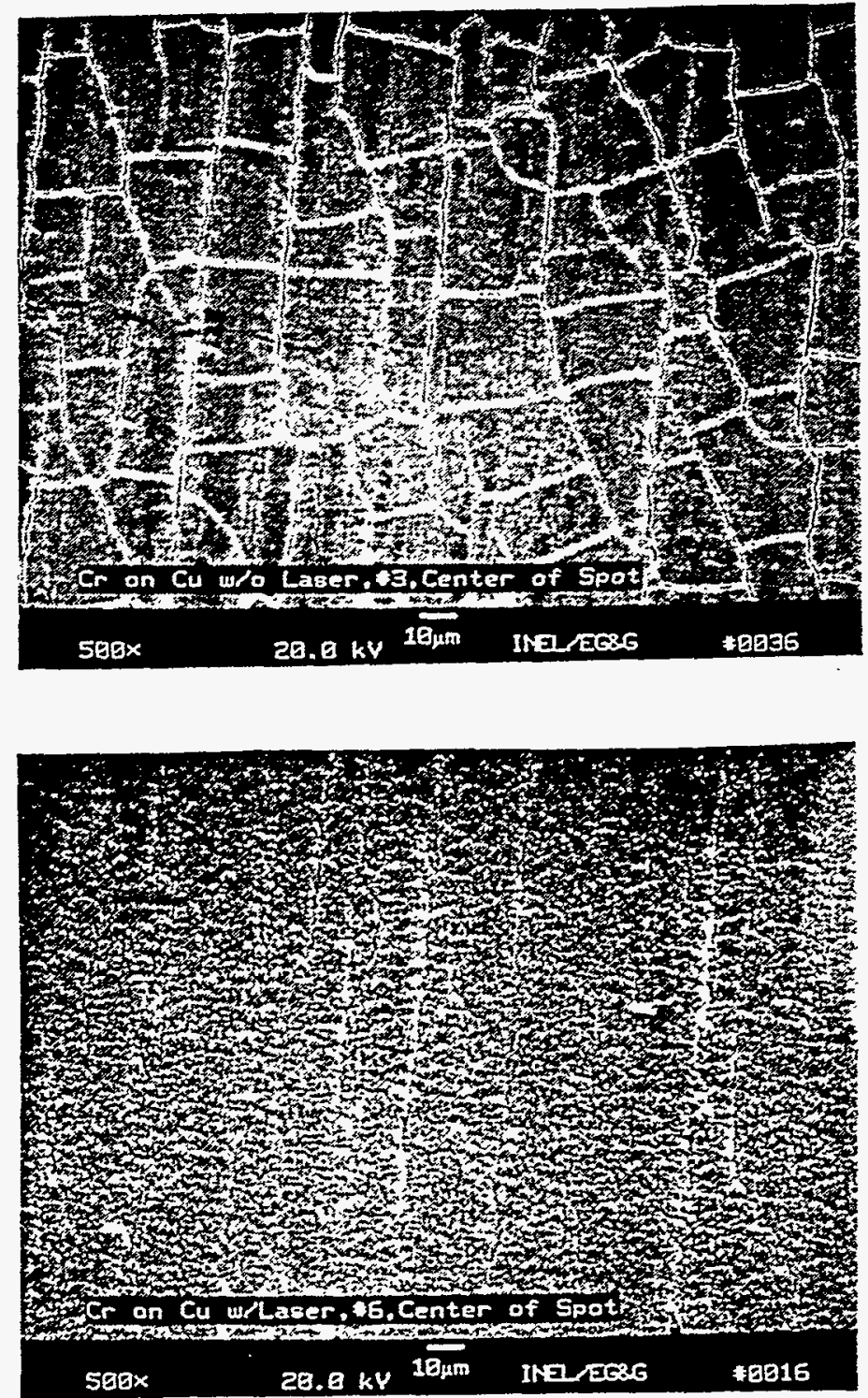

Figure 4. SEM photographs of chromium electroplate. 
surface of the jet-plated chromium shows a high degree of "chicken wire cracking." The major cause of these cracks in chromium deposits is believed to be the result of decomposition of unstable chromium hydrides $\left(\mathrm{Cr}_{2} \mathrm{H}\right)$. These hydrides are formed during the electrodeposition process in which hydrogen evolution is a competing reaction. With laser assistance, however, a crack-free deposit is formed.

Differences between laser- and nonlaser-assisted deposition are also evident in the hardness measurements made on the electrodeposit. Jet-plated chromium was found to have a diamond pyramid hardness (DPH) ranging between 500 and 600. Laser assistance from the ND:YAG laser increases hardness to 1200 . When the Argon Ion Laser is used during deposition, DPH readings average 1000 . Hardness for bath-plated chromium generally ranges from 700 to 900 .

Linear sweep voltammetry (Figure 5) studies of chromium deposition show the effect of laser irradiation on the electrochemistry of the deposition process. These voltammetry studies were carried out using a 1-mm diameter platinum wire working electrode mounted "end-on" in a Teflon block. The block was placed such that the flat end of the wire was centered in the impingement region of the free jet. These voltammograms indicate that laser irradiation of the cathode results in the onset of metal deposition at a lower potential than electrodeposition without the laser. Without laser irradiation, the onset of chromium deposition occurs at approximately $2.2 \mathrm{~V}$ versus a platinum reference electrode. With laser irradiation from an ND:YAG laser, the onset of deposition occurs at $1.8 \mathrm{~V}$. This shift in the I-V curve to more positive potentials has the effect of offsetting the polarization curve to higher current densities for a fixed potential and allows the deposition of chromium at potentials where less hydrogen evolution takes place.

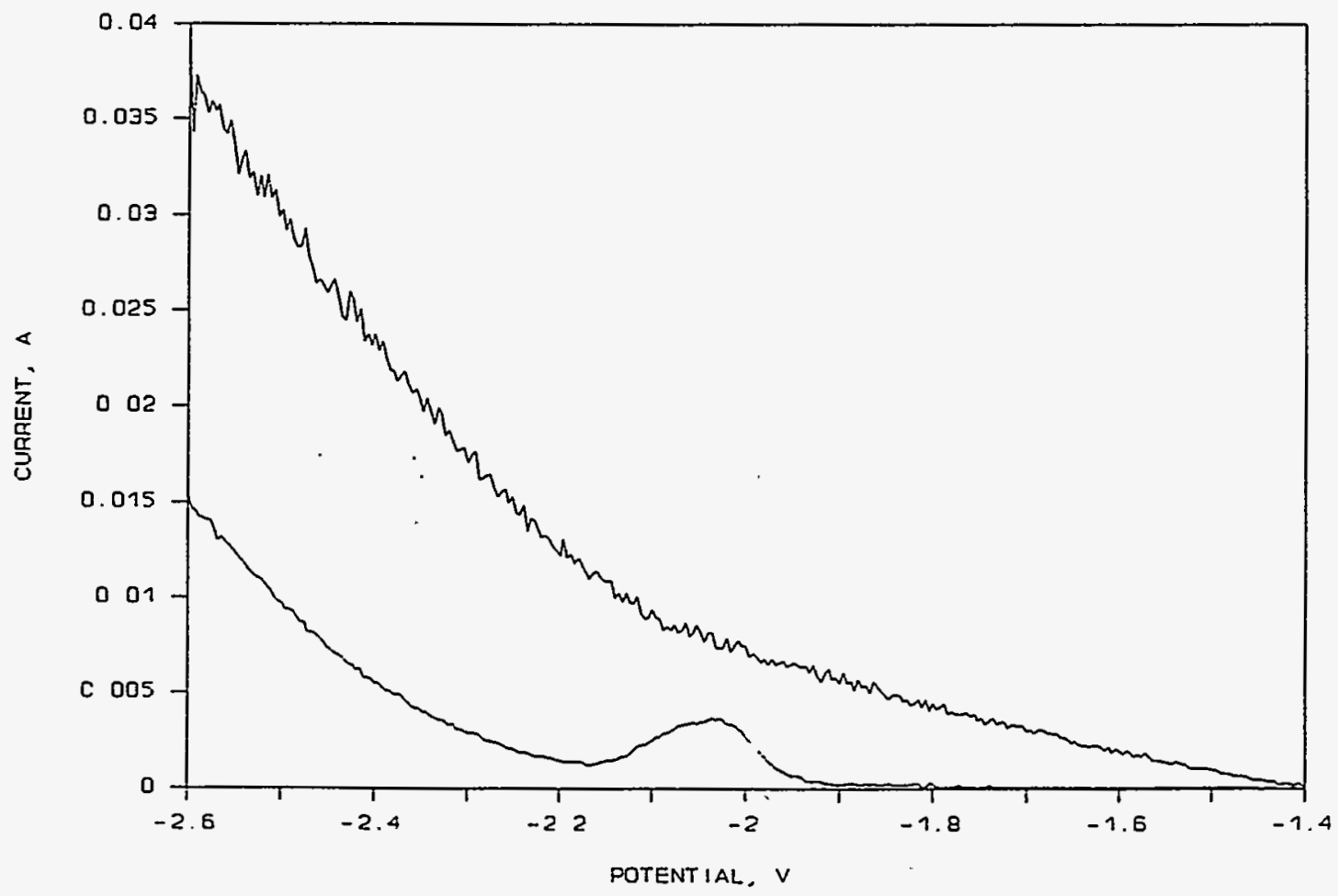

Figure 5. Linear sweep voltammograms of chromium solution with and without laser irradiation from an ND:YAG laser. 


\section{Electrode Temperature}

Because temperature plays such an important role in investigating electrode kinetics, an effort was made to measure the temperature at the surface of the electrode while under laser irradiation. This was accomplished by using the electrode/solution interface as a thermocouple. From the Nernst equation, it is clear

$E=E^{\circ}+2.3 R T / n F \log (C)$

that at equilibrium, the open-circuit potential, $\mathrm{E}$, is a function of the standard potential, $\mathrm{E}^{\circ}$, corrected for temperature, $T$, and reactant concentration, $C$. For a half-cell reaction, $\mathrm{E}^{\circ}$ is zero. Then, if $E$ is measured at a constant $C$, any change in the measured potential when the electrode is irradiated must be the result of a change in temperature at the surface of the electrode.

$\Delta \mathrm{E}=2.3 \mathrm{R} \Delta \mathrm{T} / \mathrm{nF} \log (\mathrm{C})$

To measure the surface temperature, a platinum electrode was allowed to come to equilibrium with $0.01 \mathrm{M} \mathrm{CuSO}_{4}$ in the jet cell at a flow rate of $250 \mathrm{~mL} / \mathrm{min}$. The electrode was then irradiated at $2,300 \mathrm{~W} / \mathrm{cm}^{2}$ with a ND:YAG laser, and the change in open-circuit potential was monitored with time. Results of this experiment are shown in Figure 6. Laser irradiation results in a $112 \mathrm{mV}$ cathodic shift in open-circuit potential. The observed change in potential translates into a surface temperature of $525^{\circ} \mathrm{C}$.

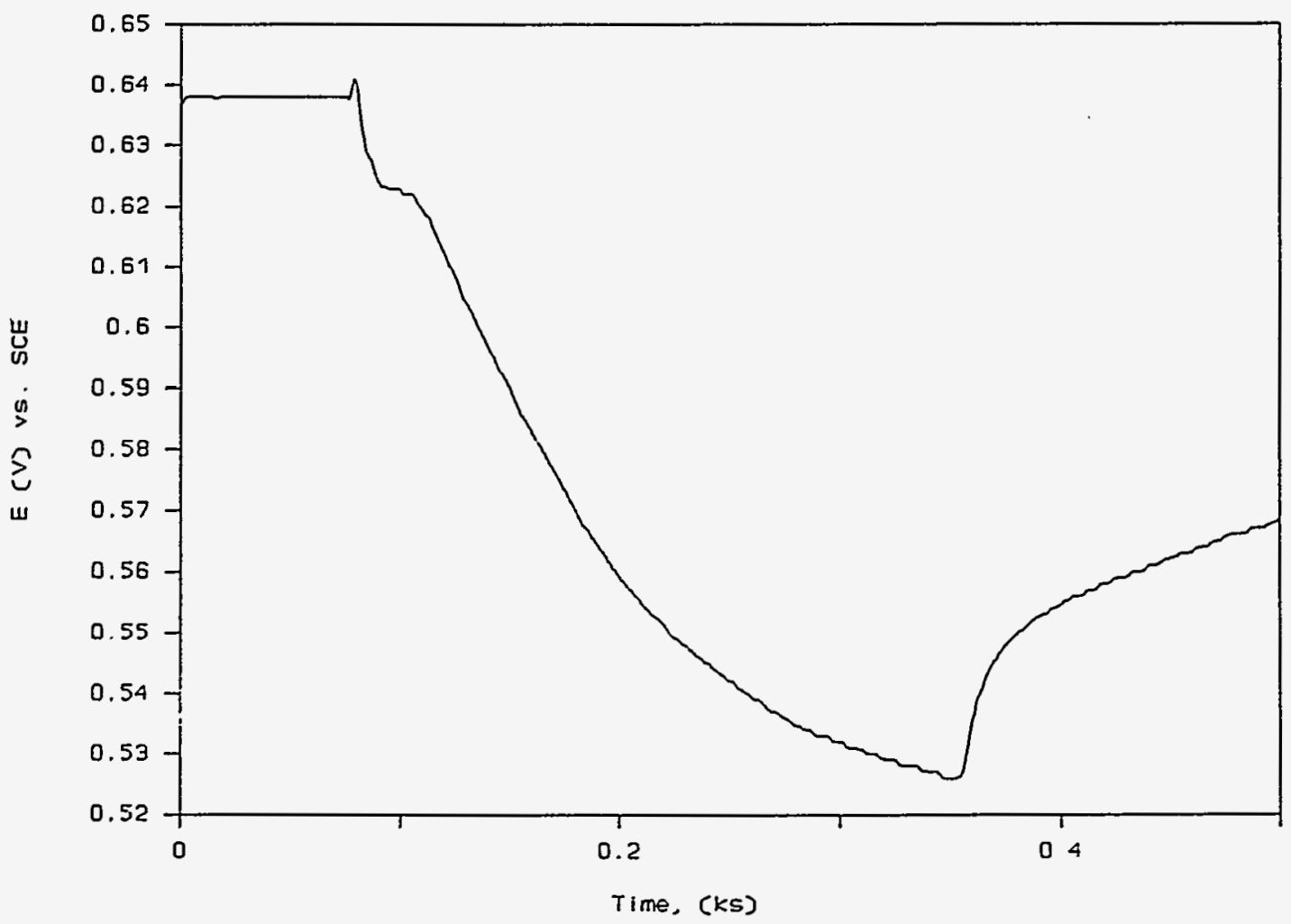

Figure 6. Open-circuit potential shift with the laser irradiation of the cathode. 
This result is an unlikely possibility. During the course of this project, laser-assisted electroplating has been carried out on lead electrodes that would have melted at this temperature. In addition, such a temperature at the surface of the platinum electrode would produce visible steam and audible boiling. Since none of the above occurs, temperature alone is insufficient to account for the change in open-circuit potential at the electrode under laser irradiation. Some addition change(s) at the electrode/solution interface must occur.

If the long-standing Nernst equation is to be believed, only temperature and concentration can affect the open-circuit potential. Therefore, to account for the shift in open-circuit potential, the electrode must not only be at a temperature different from the temperature of the bulk solution, but the concentration of ions at the surface of the electrode must be different from that of the bulk concentration. If the data in Figure 6 are closely examined, it can be seen that a small shoulder on the left-hand side of the peak is rapidly formed when the electrode is first irradiated. Over a period of 3 seconds, the open-circuit potential changes by $17 \mathrm{mV}$. If this change is attributed to a change in temperature, an electrode surface temperature of approximately $99^{\circ} \mathrm{C}$ is calculated from the Nernst equation. The remaining $95 \mathrm{mV}$ change in potential can then be attributed to a change in concentration at the electrode surface. An "apparent" copper concentration of $5 \mathrm{~mol} / \mathrm{L}$, or 500 times higher than the bulk concentration of the solution, is required to account for this shift in potential. Thus, the electrode irradiated with a high-intensity laser beam "sees" far greater concentration than exists in the bulk solution.

\section{Electroplating Enhancement Mechanism}

It is known that a temperature gradient at a metal/solution interface can result in the migration of ions in the solution to either the hot or cold region, thus producing a corresponding concentration gradient. This concentration gradient arises because the temperature gradient affects a Gibbs energy gradient for each of the ions in solution. Certain ions in the solution are driven toward the metal, thereby increasing the surface concentration; while other ions are driven away from the surface, producing a interfacial concentration below that of the bulk solution., ${ }^{1,2}$ This phenomenon is known as the Soret effect, and it occurs in both gases and liquids. A representation of this effect is shown in Figure 7. The Soret effect has been suggested as a possible mechanism for differentiating minerals in cooling magna and for increasing corrosion rates in high-temperature environments. ${ }^{3}$

We postulate that the Soret effect is the major contributing factor to the plating rate enhancement mechanism. While this does not preclude the possibility of other contributing effects of laser irradiation, such as photochemical influence, the Soret effect can be used to explain data obtained in this investigation. Because the Soret effect increases the concentration of metal ions at the surface of the electrode, higher current efficiencies would be expected and these would translate into increased plating rates. In addition, an increased concentration of metal ions at the surface of the electrode results in electrodeposition at potentials less negative than would be required by the bulk concentration of the solution. 


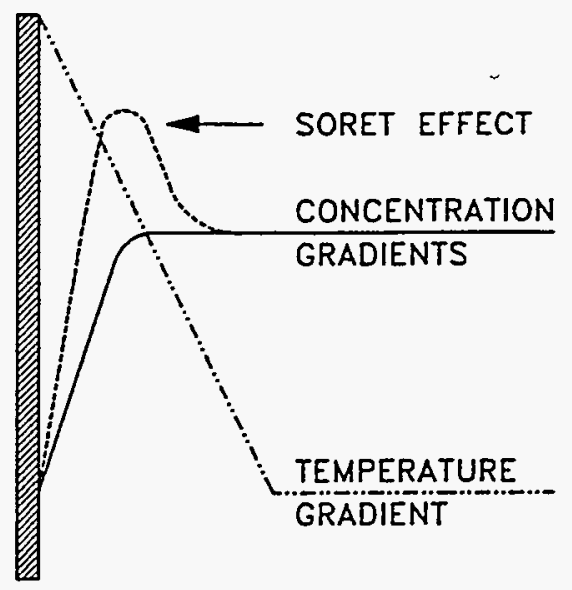

Figure 7. Soret effect from a model by Smalley et al. ${ }^{3}$

\section{Alloy Plating}

The effect of laser irradiation on the complex codeposition of both iron-nickel and zinc-nickel alloys was investigated in FY-91. Zinc-nickel codeposition was chosen because of the alloy's value as a corrosion-resistant coating. Iron-nickel codeposition was chosen for this study because of its value as the magnetic alloy, Permalloy.

In addition to their practical applications, deposition studies of both alloys are of interest because of the anomalous nature of their deposition behavior. During the codeposition of iron-nickel and zinc-nickel alloys, the less noble metal deposits at a faster rate than nickel. In single metal deposition, the opposite effect is observed. Although the standard potentials for nickel, iron, and zinc are $-0.25 \mathrm{~V},-0.41 \mathrm{~V}$, and $-0.76 \mathrm{~V}$, respectively, their relative plating rates when codeposited are $\mathrm{Zn}>\mathrm{Fe}>\mathrm{Ni}$, the reverse of what would be predicted from reduction potentials. This phenomenon is called anomalous codeposition.

The composition of an iron-nickel electroplate, codeposited from a simple 50/50 solution of iron and nickel sulfate in dilute $\mathrm{H}_{2} \mathrm{SO}_{4}$, both with and without laser assistance, is listed in Table 2. Composition of electrodeposited alloys was determined by dissolving the deposit and substrate in sulfuric acid and by analyzing the resulting solution via inductively coupled plasma (ICP). At low applied current $(5 \mathrm{~mA})$, nickel deposits from this solution at a rate almost equal to that of iron, producing an electrodeposit containing $42 \%$ nickel. At higher currents, the plating rate for nickel is dramatically suppressed. At an applied current of $20 \mathrm{~mA}$, only $3 \%$ of the deposited metal is nickel even though nickel ions make up $50 \%$ of the metal ions in the solution. Similar results were obtained in the electrodeposition of $\mathrm{Zn}-\mathrm{Ni}$ alloys.

Comparing this data with that in the literature ${ }^{4,5,6}$ indicates that jet electroplating these alloys produces an extreme example of anomalous codeposition. Laser irradiation of the substrate, with an ND:YAG laser, does increase the overall deposition rate of metal and slightly increases the percentage of nickel in the electrodeposit. However, the addition of the laser to the process is not useful in overcoming the anomalous nature of the codeposition process. 
Table 2. Composition of iron-nickel electroplate as a function of applied current, with and without laser irradiation.

\begin{tabular}{|c|c|c|c|c|c|c|}
\hline \multirow[b]{2}{*}{$\begin{array}{c}\text { Applied } \\
\text { current } \\
(\mathrm{mA})\end{array}$} & \multicolumn{3}{|c|}{ Jet } & \multicolumn{3}{|c|}{ Laser } \\
\hline & $\begin{array}{c}\mathrm{Ni} \\
(\%)\end{array}$ & $\begin{array}{c}\mathrm{Fe} \\
(\%)\end{array}$ & $\mu \mathrm{g} / \mathrm{min}$ & $\begin{array}{c}\mathrm{Ni} \\
(\%)\end{array}$ & $\begin{array}{c}\mathrm{Fe} \\
(\%)\end{array}$ & $\mu \mathrm{g} / \mathrm{min}$ \\
\hline 20 & 3 & 97 & 167 & 7 & 93 & 180 \\
\hline 15 & 5 & 95 & 75 & 8 & 92 & 118 \\
\hline 10 & 8 & 92 & 35 & 12 & 88 & 56 \\
\hline 5 & 42 & 58 & 4 & 45 & 55 & 6 \\
\hline
\end{tabular}

Energy Dispersive X-Ray Spectrometry (EDS), performed in the scanning electron microscope at several points across the surface of the alloy electrodeposits, indicates that the composition of the alloy varies as a function of the distance from the impingement region of the jet. The nickel content of the deposits is very low at the center and increases near the edge. This is likely the result of uneven current distribution across the wall jet. Because the anode is located behind the nozzle in the upstream portion of the jet, the only current path in the cell is the free jet itself. The current density would then be expected to be highest in the center of the wall jet (i.e., the stagnation point) and to decline as the wall jet expands in the radial direction and as the fluid layer becomes very thin. The high resistance in the thin layer of fluid would result in declining current density in the radial direction. Thus, composition of the alloy deposit is affected.

It is clear from these experiments that the laser-induced Soret effect is of no practical value in overcoming the anomalous nature of $\mathrm{Fe}-\mathrm{Ni}$ and $\mathrm{Zn}-\mathrm{Ni}$ alloy deposition from simple solutions. Attempts to explain this anomalous codeposition generally invoke the formation of ferrous hydroxide or zinc hydroxide when the current density is high enough to significantly increase $\mathrm{pH}$ at the cathode. Increased $\mathrm{pH}$ is followed by selective adsorption of the hydroxide on the cathode, allowing iron or zinc to deposit freely, but impeding nickel deposition. ${ }^{7}$ If hydroxide formation is the cause of anomalous codeposition, then the Soret effect is of little assistance in controlling the $\mathrm{pH}$ at the surface of the electrode or in preventing adsorption of the hydroxide.

It is also clear that the deposition of nickel-rich alloys such a Permalloy $(80 \% \mathrm{Ni}, 20 \% \mathrm{Fe})$ would require solutions containing a large excess of nickel. In addition, uniform deposits of both $\mathrm{Fe}-\mathrm{Ni}$ and $\mathrm{Zn}-\mathrm{Ni}$ alloys have proven very difficult to obtain in a free-jet plating system. While the high mass transfer rate in the jet facilitates increased plating rates, current distribution across the jet produces a deposit with varying composition. More uniform deposits might be obtained with a submerged jet system. However, due to the nature of wall jets, edge effects might still be difficult to eliminate. 


\section{Difficult-to-Deposit Metals}

Perhaps more effort has been expended by researchers on attempts to electrodeposit tungsten and molybdenum than on any other elements. Despite this effort, there is no conclusive evidence that either metal has been successfully deposited, in pure form, from aqueous solutions. ${ }^{8}$ Both metals have low hydrogen overpotentials and will, therefore, not deposit on themselves. As soon as a monatomic layer is formed, deposition of metal ceases and the hydrogen ions in the plating solution are preferentially reduced.

Initial efforts to deposit molybdenum and tungsten from the laser jet system were made from simple dilute solutions $(100 \mathrm{~g} / \mathrm{L})$ of ammonium molybdate and sodium tungstate, respectively. In both cases, the experiments produced a shiny, black circular deposit containing a copper-colored area at the center. Laser irradiation with the ND:YAG laser resulted in a smaller black area and a center that contained a powdery gray material. Both deposits could be easily wiped off the substrate. Auger analysis of the deposits indicated a very high oxygen content, leading to the conclusion that these deposits comprised various oxides of the metals.

Additional efforts to deposit both molybdenum and tungsten were made from a solution containing the metal salts and $\mathrm{Na}_{2} \mathrm{PO}_{4}$ to lower the $\mathrm{pH}$ of the solution. Electrodeposition from the jet produced a thin layer of silver-gray material that did not increase in thickness with increased plating time. Laser irradiation with the ND:YAG laser allowed a slow buildup of a silver-grey deposit. Auger analysis indicates that the oxygen content of the deposits was much lower than that of the previous deposits. It is believed that these deposits consisted of nearly pure metals.

Results of these experiments are quite encouraging. They indicate that, with laser assistance, tungsten and molybdenum might well be deposited in pure form from solutions containing the proper constituents to adjust the plating chemistry.

\section{Electrochemical Milling}

Preliminary experiments in laser-assisted electrochemical milling were performed in FY-90. In these experiments, electrode polarity was reversed so that the jet impinged on the anode while the cathode was located behind the nozzle. Using sodium chloride as the electrolyte, 0.01 in. thick steel shim stock was milled. It was found that, unlike electrodeposition in the jet system, where metal is deposited only in the impingement region, milling with the jet removes metal from the entire wall-jet region. This lack of cutting precision at constant current makes the jet system less than ideal for milling applications. However, it was determined that laser irradiation of the substrate did increase the milling rate. It is believed that with better control of the electrolyte flow system (for example, in a thin film flow cell) laser-assisted electrochemical milling could become a viable process for very precise small-scale milling.

\section{Hydrogen Evolution Reaction}

The hydrogen evolution reaction (HER) has been studied extensively since the last century. Because it is a fundamental electrochemical reaction and often a competing process in 
electrodeposition, the effect of laser irradiation on this reaction was investigated during the final year of this project.

In studies of the HER, a multistep mechanism comprising three reactions is usually presumed. In acid solutions, the first step is an electroreduction of the hydronium ion $\left(\mathrm{H}_{3} \mathrm{O}^{+}\right)$, leading to the adsorption of hydrogen $\left(\mathrm{H}_{\mathrm{ads}}\right)$ at an active site $(\mathrm{M})$ on the electrode surface (Volmer reaction [3]). This reaction is followed by an electrochemical desorption step (Heyrovsky reaction [4]), and/or a recombination step (Tafel reaction [5]).

$$
\begin{aligned}
& \mathrm{M}+\mathrm{H}_{3} \mathrm{O}^{+}+\mathrm{e}^{-}->\mathrm{MH}_{\mathrm{ads}}+\mathrm{H}_{2} \mathrm{O} \\
& \mathrm{MH}_{\text {ads }}+\mathrm{H}_{3} \mathrm{O}^{+}+\mathrm{e}^{-}-->\mathrm{M}+\mathrm{H}_{2}+\mathrm{H}_{2} \mathrm{O} \\
& \mathrm{MH}_{\text {ads }}+\mathrm{MH}_{\mathrm{ads}} \rightarrow 2 \mathrm{M}+\mathrm{H}_{2}
\end{aligned}
$$

The mechanism of this multistep process is determined from the rate-determining step (rds). Identification of the rds and estimation of the reaction mechanism are generally accomplished through analysis of the slope of the polarization curve (Tafel slope) near the onset of the HER. The slope (b), at low overpotentials, is equal to $2.303 \mathrm{RT} / \alpha \mathrm{F}$, where $\alpha$ is the charge-transfer coefficient and $\mathrm{R}, \mathrm{T}$, and $\mathrm{F}$ have their usual meaning. Although simplified, it is widely accepted that the value of the charge-transfer coefficient $(\alpha)$ depends on the rds for multistep reactions. When the rds is Equation (3), or Equation (3) coupled with Equation (4), or Equation (3) coupled with Equation (5), the value of $\alpha$ is 0.5 . This corresponds to a Tafel slope (b) of 116 $\mathrm{mV} /$ decade of current at a temperature of $293 \mathrm{~K}\left(20^{\circ} \mathrm{C}\right)$. When Equation (4) is the rds, $\alpha=1.5$ and $b=38.7 \mathrm{mV} /$ decade. When Equation (5) is rds, $\alpha=2$ and $b=29 \mathrm{mV} /$ decade.

Considerable difficulty was encountered in obtaining reproducible cathodic Tafel plots at a platinum electrode using standard linear polarization techniques due to the electrodeposition of solution impurities while the electrode was under cathodic polarization. Because the electrocatalytic activity of platinum and the mechanism of the HER are strongly dependent on the cleanliness of the electrode surface, Tafel plots for the hydrogen reaction were obtained using a potential step technique. In this technique, the electrode potential is initially held at an anodic potential $(1.4 \mathrm{~V})$ for a time and then stepped to the cathodic potential of interest, the current transients are recorded, and the potential stepped back to an anodic potential to oxidize the adsorbed hydrogen and to remove any impurities deposited during cathodic polarization. The currents recorded from 700 to $900 \mathrm{~ms}$ at each potential were averaged to produce each data point for the Tafel plots.

Figure 8 shows Tafel plots developed for the platinum electrode in $0.5 \mathrm{M} \mathrm{H}_{2} \mathrm{SO}_{4}$ at a solution temperature of $20^{\circ} \mathrm{C}$ without laser irradiation and at three laser power densities. The Tafel parameters are tabulated in Table 3. The Tafel plot for the hydrogen reaction on platinum in the jet cell exhibits a linear region with a slope of $36 \mathrm{mV} /$ decade. Solving the Tafel slope expression $(b=R T / \alpha F)$ for the charge transfer coefficient, $\alpha$, gives a value of 1.6 . This result indicates a parallel reaction mechanism for the HER. The mechanism consists of the adsorption step (Equation [3]) followed by both electrochemical (Equation [4]) and chemical desorption (Equation [5]) steps. In acid solution, the adsorption step is considered to be at quasi-equilibrium 


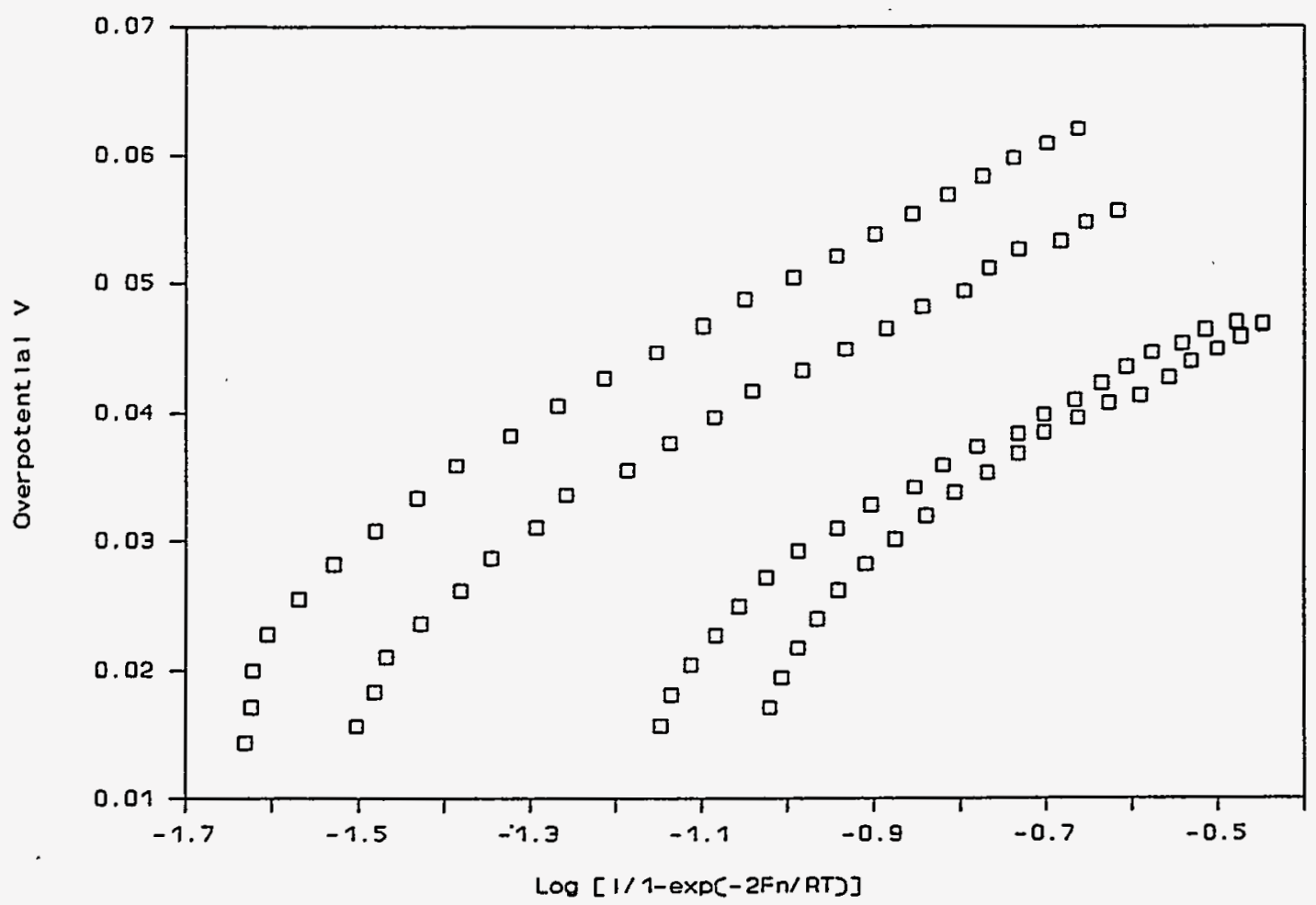

Figure 8. Tafel plots for the HER on $\mathrm{Pt}$ in $0.5 \mathrm{M} \mathrm{H}_{2} \mathrm{SO}_{4}$ without laser irradiation $(P=0)$ and with laser irradiation $\left(P=130,800\right.$, and $\left.2,300 \mathrm{~W} / \mathrm{cm}^{2}\right)$.

Table 3. Tafel parameters for the HER as a function of laser power density.

\begin{tabular}{cccc}
$\begin{array}{c}\text { Laser power } \\
\left(\mathrm{W} / \mathrm{cm}^{2}\right)\end{array}$ & $\begin{array}{c}\text { Tafel slope } \\
(\mathrm{mV} / \mathrm{dec} \text { ede })\end{array}$ & $\begin{array}{c}\text { Charge } \\
\text { transfer } \\
\text { coefficient } \\
(\boldsymbol{\alpha})\end{array}$ & $\begin{array}{c}\text { Exchange } \\
\text { current } \\
\left(\mathrm{A} / \mathrm{cm}^{2}\right)\end{array}$ \\
\hline 0 & 36 & 1.6 & $4.0 \times 10^{-3}$ \\
130 & 34.3 & 1.7 & $5.7 \times 10^{-3}$ \\
800 & 33.8 & 1.8 & $13 \times 10^{-3}$ \\
2,300 & 33.6 & 2.0 & $14 \times 10^{-3}$ \\
\hline
\end{tabular}

and the electrochemical step provides the major contribution to the reaction rate at low overpotentials (i.e., it is the slowest of the three reactions). This result is in agreement with typical literature values. ${ }^{9}$ 
Tafel slopes obtained while the electrode was irradiated by a ND:YAG laser display only minor changes in slope with increasing laser power. However, the exchange current density and charge transfer coefficients increase with increasing laser power. The charge transfer coefficients were determined from the Tafel slope, using the temperature at the surface of the electrode calculated from the previously described temperature measurement utilizing the Nernst equation. The increasing charge transfer coefficients indicate a shift in the mechanism of the hydrogen reaction with increasing laser power. This change in mechanism may be a function of the laser-induced Soret effect. If the $\mathrm{H}_{3} \mathrm{O}^{+}$concentration increases at the surface of the electrode as a result of the Soret effect, these ions would be more readily available for the electrochemical desorption reaction. Consequently, the electrochemical desorption step (Equation [4]) would become the dominant reaction for hydrogen evolution, while the recombination step would become rate limiting.

\section{Oxygen Evolution Reaction}

The effect of laser irradiation on the oxygen evolution reaction (OER) was investigated at a platinum electrode in $0.1 \mathrm{M} \mathrm{H}_{2} \mathrm{SO}_{4}$. Although platinum is a poor catalyst for the OER compared to various metal oxide electrodes, it was chosen for this study because it serves as a model electrode in studies of the mechanism of the OER and of catalytic factors affecting reaction rates.

In acid solutions, a linear $E$ versus $\log \mathrm{i}$ relationship has been reported for the OER with a Tafel slope of approximately $2 \mathrm{RT} / \mathrm{F}$ or $120 \mathrm{mV}$ for several decades as the logarithm of current density. This slope has been associated with the first electron transfer process being the rate-determining step with $\mathrm{H}_{2} \mathrm{O}$ in the double layer as the reactant. ${ }^{10}$ Furthermore, it is known that a thin, insulating $\mathrm{Pt}$ oxide film covers the electrode surface in the potential region of the OER and that its presence hinders the rate of the OER. An important characteristic of the OER at $\mathrm{Pt}$ is that a constant Tafel slope of $120 \mathrm{mV} /$ decade, at room temperature, can be observed only when the electrode is anodically pretreated. ${ }^{11}$ During pretreatment, an oxide film grows over the electrode surface. Variations in Tafel slope can usually be related to variations in the thickness and uniformity of this oxide film.

Tafel plots for the OER both with and without laser irradiation are shown in Figure 9. These Tafel plots were obtained by anodically pretreating the electrode at $10^{-3} \mathrm{~A} / \mathrm{cm}^{2}$ for $100 \mathrm{~s}$ and scanning the voltage, at $1 \mathrm{mV} / \mathrm{s}$, from $2.00 \mathrm{~V}$ to $1.4 \mathrm{~V}$ versus SCE. Without laser irradiation, two linear regions are obtained in the Tafel slope. Above $1.7 \mathrm{~V}$, a slope of $126 \mathrm{mV} /$ decade is observed; and below $1.7 \mathrm{~V}$, a slope of $200 \mathrm{mV} /$ decade is seen. At high overpotential, the slope is near literature values ${ }^{7}$ and corresponds with the mechanism:

$$
\begin{aligned}
& \mathrm{M}+\mathrm{H}_{2} \mathrm{O}-->\mathrm{MOH}_{\mathrm{abs}}+\mathrm{H}^{+}+\mathrm{e}^{-} \\
& 4 \mathrm{MOH}_{\mathrm{abs}}<-->4 \mathrm{M}+\mathrm{O}_{2}+\mathrm{H}_{2} \mathrm{O}
\end{aligned}
$$

With laser irradiation at a power density of $2,300 \mathrm{~W} / \mathrm{cm}^{2}$, a Tafel slope of $162 \mathrm{mV} /$ decade is recorded. This Tafel slope is consistent with the expected increase in slope, if the temperature at the electrode surface is taken to be $100^{\circ} \mathrm{C}$. This result indicates that the laser irradiation has no effect on the OER under these experimental conditions. This observation is consistent with the 


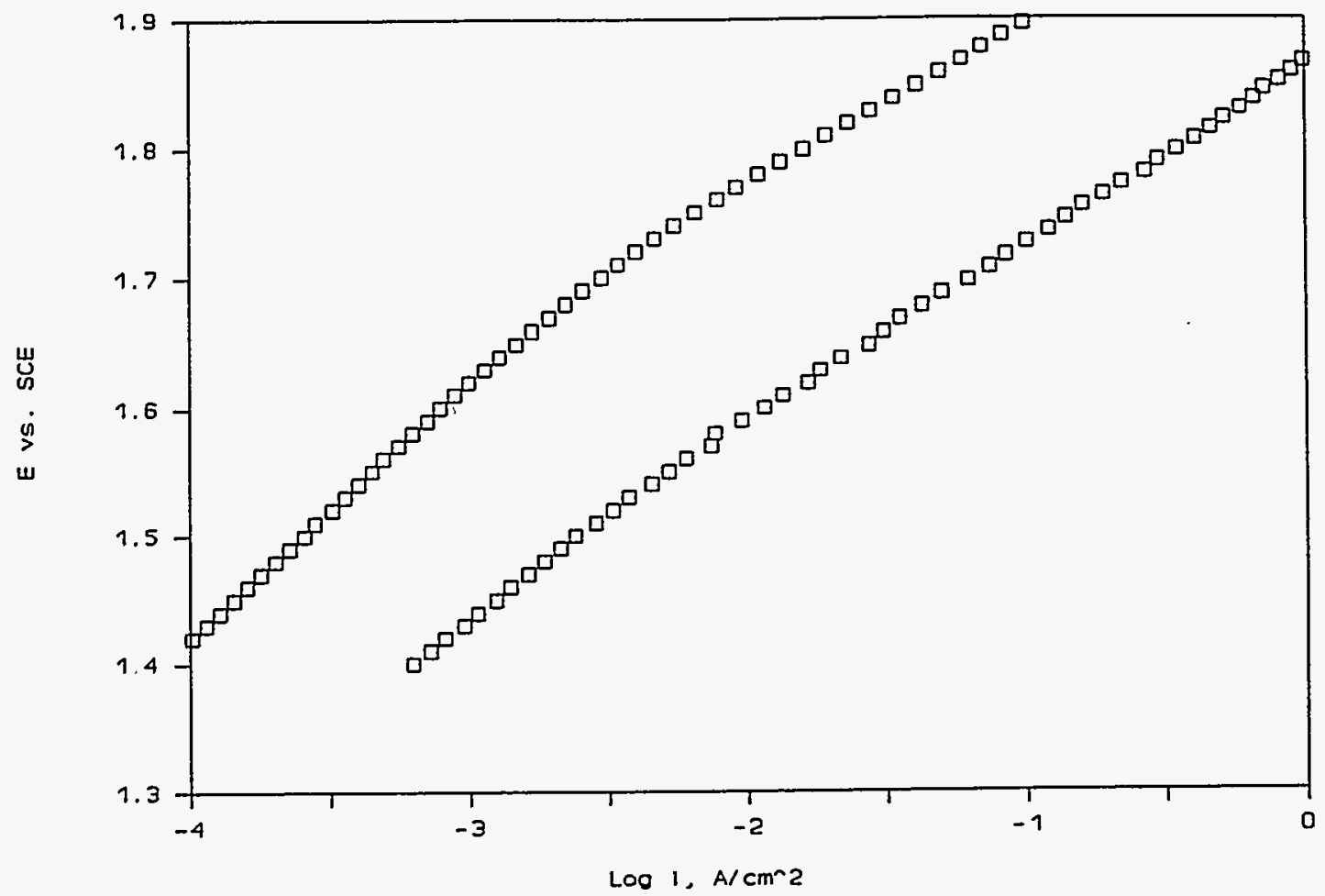

Figure 9. Tafel plots for the OER on $\mathrm{Pt}$ in $1 \mathrm{M} \mathrm{H}_{2} \mathrm{SO}_{4}$ without laser irradiation $(\mathrm{P}=0)$ and with laser irradiation $\left(P=2,300 \mathrm{~W} / \mathrm{cm}^{2}\right)$.

laser-induced Soret effect. Since $\mathrm{H}_{2} \mathrm{O}$ is the reactant for the OER in acid solution, it would be unaffected by the Soret effect. 


\section{CONCLUSIONS}

The effect of laser irradiation on electrodeposition processes has been investigated. These studies demonstrated that the addition of laser irradiation to an electroplating process can dramatically enhance plating rates and current efficiencies, as well as improve the morphology of the resultant electrodeposit. During the course of these investigations, the mechanism for the laser enhancement of electrodeposition processes was determined. Experimental evidence was obtained to show that laser irradiation of the substrate results in increased metal ion concentrations at the surface of the electrode due to a laser-induced Soret effect.

The laser-induced Soret effect has important implications for laser-assisted electrochemical processing. The increase in the surface concentration of ions allows efficient electrodeposition from dilute solutions. As such, laser-assisted electrodeposition may develop into an environmentally conscious manufacturing process by reducing waste and limiting worker exposer to toxic chemicals. This unique ability of the process to efficiently deposit metals from dilute solutions may also find use in the recovery of high-value metals. Because increased surface concentration results in electrodeposition at a potential lower than required for deposition at the bulk concentration, the laser can be used to drive the deposition process. That is, the potential at the substrate can be set at a voltage less than that required for deposition from the bulk concentration. When the substrate is irradiated, deposition will occur only where the laser beam is focused, because the increased concentration at the electrode will lower the deposition potential in that area of the substrate. This technique can, therefore, be used to direct-write the metal on the substrate. Very precise movement of the laser beam could make it possible to use this process to manufacture micro-machines. Micro-machines are microscopic valves, sensors, and motors produced either free standing or etched into various materials to monitor and react to structural vibrational modes, stresses, fatigue, and damage. The unique operating parameter provided by the laser also offers the possibility of applications in other electrochemical processes such as electrowinning and electrorefining and in improving the performance of various electroanalytical techniques. 


\section{REFERENCES}

1. J. F. Smally, C. V. Krishnan, M. Goldman, and S. W. Felberg, J. Electroanal. Chem., 248 , p. 255, (1988).

2. J. F. Smally, R. A. MacFarquhar, and S. W. Feldberg, J. ElectroanaL Chem., 256, p. 21, (1988).

3. V. A. Pugin and N. Sh. Bagdasarov, Geokhimiya, 9, p. 1,285, (1987).

4. D. Gangasingh and J. Talbot, J. Electrochem. Soc., 138, p. 3,605, (1991).

5. D. Grimmett, M. Schwartz, and K Nobe, J. Electrochem. Soc., 137, p. 3,414, (1990).

6. H. Dahms and I. M. Croll, J. Electrochem. Soc., 112, p. 771, (1965).

7. I. Croll and L. Romankiw, Electrodeposition Technology, Theory and Practice, Romankiw, L. T. (ed.), Electrochemical Society, Inc.: Pennington, NJ, p. 285, (1987).

8. A. G. Gray, Modern Electroplating, John Wiley \& Sons, Inc., New York, p. 497, (1953).

9. B. E. Conway and Lijun Bai, J. Electroanal. Chem., 198, p. 149, (1986).

10. A. Damjanovic, V. I. Briss, and D. S. Boudreauz, J. Electrochem. Soc., 138, No. 9, p. 2,549, (1991).

11. J. Horiuti, Physical Chemistry, An Advanced Treatise, IXB, H. Eyring (ed.), Academic Press, NY, (1970). 
